\title{
The Shifting Landscape of Ratepayer-Funded Energy Efficiency in the U.S.
}

An unprecedented expansion of ratepayer-funded energy efficiency is underway. Can it be done, and what are the implications for the country's broader energy goals and energy policies?

Authors: Galen Barbose ${ }^{1}$, Charles Goldman ${ }^{1}$, Jeff Schlegel ${ }^{2}$

${ }^{1}$ Lawrence Berkeley National Laboratory

${ }^{2}$ Independent Consultant

Acknowledgements: This work was supported by the Office of Electricity Delivery and Energy Reliability and by the Office of Energy Efficiency and Renewable Energy, Weatherization and Intergovernmental Program of the U.S. Department of Energy under Contract No. DE-AC0205CH11231.

\section{Introduction}

Over the last two decades, utility ratepayer funding for energy efficiency has seen both booms and busts. Currently, about 35 states implement ratepayer-funded energy efficiency programs, with a total U.S. budget of $\$ 3.1$ billion in 2008, approximately $80 \%$ of which is concentrated in just ten states. ${ }^{1}$ However, a proliferation of new state-level policies enacted over the past several years suggests that the next decade may see a dramatic and sustained increase in overall funding levels, and a fundamental re-drawing of the energy efficiency map. These new state energy efficiency policies reflect a variety of concerns, including the increasing cost and siting challenges of building new generation and transmission, fuel cost and supply risks, and the potential cost of future carbon regulations.

For example, within the past three years, eleven states have adopted energy efficiency portfolio (or resource) standards (EEPS or EERS), which establish specific long-term savings targets that utilities are obligated to meet, and at least three other states are currently considering doing so.

Several states have also passed legislation requiring utilities to acquire all available cost-effective energy efficiency. Regulators in several Western states have also recently revised integrated resource planning (IRP) and demand-side management (DSM) planning rules to require more robust analysis of the resource potential and benefits of energy efficiency, which has resulted in increased savings targets for their energy efficiency portfolios. ${ }^{2}$ Finally, regulators and utilities in many states are beginning to look more closely at regulatory incentive mechanisms to better align utility financial interests with improvements in customer energy efficiency.

We examined energy efficiency policies and legislative statutes on the books or in the pipeline in all 50 states and developed low, medium and high projections of future energy efficiency spending and savings. Depending on how aggressively and effectively states implement these policies, we estimate that spending on ratepayer-funded energy efficiency could increase from $\$ 3.1$ billion in 2008 to more than $\$ 12$ billion (nominal dollars) per year by 2020 in our high case, a growth rate in spending of about $12 \%$ per year. Annual electricity savings nationally could triple from an estimated $0.3 \%$ of retail electricity sales in 2008 to $0.9 \%$ of retail electricity sales 
in 2020. In the low and medium scenarios, ratepayer funding for electric and gas energy efficiency in the U.S. would increase to \$5.4 and \$7.5 billion, respectively, by 2020.

What are the implications of such a scale-up of ratepayer-funded energy efficiency at the state level for national energy policy, such as a national EEPS or future carbon regulations? Can a ramp-up of this scale be achieved, and what practical constraints might slow these efforts?

\section{Recent Developments and Trends in Ratepayer-Funding for Energy Efficiency Programs}

Table 1 shows the 2008 approved electric and gas energy efficiency program budgets for the topten states, all other states, and the U.S. total. Over $80 \%$ of the national total (\$3.1 billion) came from electric ratepayers (\$2.6 billion), while gas utilities were authorized to spend about $\$ 0.5$ billion on energy efficiency programs. ${ }^{3}$ The 2008 budget total represents approximately a 20\% increase over the $\$ 2.6$ billion combined electric and gas budget in 2007. The top 10 states account for about $78 \%$ of the total U.S. energy efficiency budget, each of which planned to spend \$100 million or more in 2008. California, the heavyweight in terms of the absolute magnitude of its spending on energy efficiency, represented one-third of the total U.S. energy efficiency program budget in 2008.

Table 1. 2008 Ratepayer-Funded EE Budgets

\begin{tabular}{|cc|ccc|}
\hline \multirow{2}{*}{ Rank } & \multirow{2}{*}{ State } & \multicolumn{3}{|c|}{ 2008 Budget (\$M) } \\
\cline { 3 - 5 } & & Electric & Gas & Total \\
\hline 1 & CA & 831 & 183 & 1,014 \\
2 & NY & 258 & 30 & 288 \\
3 & NJ & 135 & 61 & 196 \\
4 & WA & 160 & 18 & 179 \\
5 & MA & 121 & 28 & 149 \\
6 & WI & 76 & 64 & 140 \\
7 & MN & 106 & 30 & 137 \\
8 & FL & 109 & 15 & 124 \\
9 & CT & 107 & 7 & 114 \\
10 & TX & 106 & no data & 106 \\
\hline All Other States & 592 & 94 & 686 \\
\hline \multicolumn{2}{|c|}{ U.S. Total } & 2,603 & 529 & 3,132 \\
\hline
\end{tabular}

Source: Consortium for Energy Efficiency (CEE); excludes budget for load management programs. Note that a number of small states have relatively aggressive energy efficiency budgets in proportion to their population and retail electricity and gas sales (e.g., VT, OR, ID, IA, RI, NH, UT).

A proliferation of state-level energy efficiency policies adopted over the past several years suggests that the energy efficiency landscape in the U.S. may be on the verge of dramatic change, with an unprecedented expansion of ratepayer funding and a far-reaching geographical re-alignment of the energy efficiency marketplace. To understand these trends, it is helpful to classify states into three rough groupings: Leaders, Up-and-Comers, and Uncommitted States. 


\section{A. Leaders}

Over the past 5-10 years, approximately 15 states have maintained relatively significant ratepayer-funding for energy efficiency programs (i.e., electric energy efficiency budgets equal to $1 \%$ or more of revenues from retail electricity sales, and annual electric savings equal to at least $0.5 \%$ of retail sales). Many of these leading states are listed in Table 1 , although some have relatively small populations and thus have energy efficiency budgets that are small in absolute magnitude but large on a per-capita basis (e.g., Vermont, Rhode Island, and Oregon). In most leading states, the underlying policy support for energy efficiency program spending has been provided through integrated resource (or DSM-specific) planning and/or systems benefit funding mechanisms, and in some leading states, through statutory requirements that utilities acquire all (achievable) cost-effective energy efficiency savings opportunities.

Going forward, all of the leading states plan to maintain strong commitments to ratepayer-funded energy efficiency, and many have recently made (or are considering) commitments to substantially expand existing efforts. For example, New York established an aggressive energy efficiency portfolio standard (EEPS) requiring ratepayer-funded electric energy efficiency programs to achieve average annual savings of approximately $1.4 \%$ of retail sales from 2009 2015, or more than double current levels. In pursuit of the new goals, the New York Public Service Commission authorized the state’s investor-owned electric utilities to spend \$330 million per year through 2011 on energy efficiency programs. ${ }^{4}$ New Jersey also recently adopted aggressive new long-term energy savings goals that triple current savings levels, reaching approximately $2 \%$ of retail sales per year. The New Jersey Board of Public Utilities recently approved expanded budgets for the state's ratepayer-funded energy efficiency programs, rising to \$325 million in 2012, in line with the long-term savings goals. ${ }^{5}$ A new EEPS policy has also been proposed in Wisconsin, which would require electric savings of $2 \%$ of retail sales per year (approximately a quadrupling of current levels) by 2015. A number of other leading states (California, Connecticut, Massachusetts, Rhode Island, and Washington) have enacted statutes that require utilities to obtain all achievable cost-effective energy efficiency opportunities. To meet these mandates, state regulators in Massachusetts and Connecticut are currently considering utility energy efficiency program plans or recommendations from appointed energy efficiency advisory boards that would double or triple 2008 spending levels by 2011, and would result in annual energy savings equivalent to $2-3 \%$ of retail energy sales. ${ }^{6}$ In the Pacific Northwest, energy efficiency budgets are also likely to increase in the coming years, in order to meet the increasing energy efficiency savings targets identified in recent resource plans filed by major utilities in the region.

In California, the California Public Utilities Commission (CPUC) adopted a Long-Term Energy Efficiency Strategic Plan in September 2008, which provides a ten-year roadmap for a significant scaling up of the state's energy efficiency efforts and sets ambitious market transformation goals (e.g., achieving zero net energy in all new residential construction by 2020, in all new commercial construction by 2030, and in 50\% of existing commercial buildings by 2030). ${ }^{7}$ California's investor-owned utilities filed new energy efficiency program plans that propose roughly a \$400 million (or 43\%) increase by 2011 above the spending level authorized for 2008. The CPUC also adopted new long-term energy savings targets which likely will reduce the funding and savings trajectory somewhat for ratepayer-funded energy efficiency programs. The 
new savings targets represent about a 50\% decline in ratepayer-funded efficiency savings by 2020 relative to 2008 levels. In adopting the lower savings targets, the CPUC relied to some extent on an updated statewide market potential study that forecasts lower remaining achievable energy efficiency savings potential. ${ }^{8}$ In short, energy efficiency will remain a cornerstone of California energy policy for the foreseeable future, although the mix of strategies and the funding and savings levels may shift over time.

\section{B. Up-and-Comers}

There is a sizable contingent of states that, at least within recent history, have provided modest or little ratepayer-funding for energy efficiency, but have recently made significant commitments to ramping up energy efficiency programs. ${ }^{9}$ Many of these up-and-coming states are located in the Midwest or Mid-Atlantic and have recently adopted aggressive EEPS policies, including: Illinois, Maryland, Michigan, New Mexico, Ohio, Pennsylvania, and Virginia (provisionally). The electric EEPS targets in most of these states rise to 1-2\% of retail sales per year within the first 5-10 years of the standard, rivaling the annual savings levels currently being achieved in only a handful of leading states. North Carolina, another state that has, until now, been relatively inactive in the energy efficiency arena, enacted a renewables portfolio standard (RPS) under which energy efficiency can meet up to $40 \%$ of the total requirements of the state's investor owned utilities (IOUs) and an unlimited amount of the publicly owned utilities' requirements. Program development efforts in many of the aforementioned states are in their early stages, although the first set of energy efficiency plans have already been approved in Illinois and Maryland, with statewide budgets ramping up to \$167 million and \$91 million, respectively, over the first three years. ${ }^{10}$

A number of other up-and-comers have historically provided consistent, but moderate, levels of ratepayer-funding for energy efficiency and are in the process of dramatically ramping up program activity - in many cases, in response to recent policy mandates. Several of the up-andcomers in this group are located in the interior West. For example, Colorado adopted an EEPS with electricity savings targets for Xcel, the state's largest utility, reaching $1.3 \%$ of retail sales by 2020. The utility's recently-approved program plan puts it on track to meet its early-year EEPS targets, with a 2010 electric energy efficiency budget of \$64 million. ${ }^{11}$ Nevada expanded its RPS in 2005 to allow energy efficiency to meet up to $25 \%$ of the total requirement, and program plans have been approved for the state's two IOUs that commit to achieving efficiency savings in excess of the maximum amount eligible under the RPS. ${ }^{12}$ In Arizona, investor-owned utilities are now required to file DSM plans, and in its most-recent IRP, Arizona Public Service proposes to increase energy efficiency funding to $\$ 90$ million in 2020, up from $\$ 23$ million in 2008 . ${ }^{13}$

\section{Uncommitted States}

Finally, in approximately 20 states, mostly located in the Southeast and parts of the Midwest, state regulators have not authorized utilities to fund energy efficiency programs, or have authorized only minimal funding levels, and have no immediate (public) plans to significantly step up their efforts. In some of these states, utilities do offer educational or general information programs related to energy efficiency, or offer audits to some customer classes or small pilot programs, but energy efficiency budgets are typically quite small (less than $0.1 \%$ of revenues), 
and programs are quite limited in scope. Going forward, some modest increase in ratepayerfunding for energy efficiency among uncommitted states is likely to occur in the face of escalating costs for new generation and the prospect of even higher costs for fossil fuel based generation as a result of future federal climate change legislation. Some utilities in these states have expressed increased interest in implementing energy efficiency programs, in many cases linking it to deployment of an advanced metering infrastructure (AMI) or approval to build new baseload generation. Already, utilities and PUCs in a number of uncommitted states are considering moderate expansions to their energy efficiency efforts (in some cases contingent on developing an attractive business model for the utility), but have not yet made significant commitments.

\section{Adding It All Up: Projected Ratepayer-Funded EE Spending}

To gauge the potential impact of existing and impending state policies, legislative requirements, regulatory decisions and integrated resource or DSM plans (see Table 2), we developed a set of projections (low, medium, and high) of ratepayer spending on electric and natural gas energy efficiency programs through 2020. These projections do not account for the approximately $\$ 11$ billion in federal funding for energy efficiency and related projects, made available through the American Recovery and Reinvestment Act (ARRA) to state and local governments, nor do the projections account for other "non-traditional” funding sources (e.g., revenues from emission auctions and from capacity market auctions). The potential significance of these additional funding sources is discussed briefly in Section V.

\section{A. Approach}

The projections for leading and up-and-coming states were developed based on varying state- or region-specific assumptions about how effectively and aggressively the energy efficiency policies currently in place (or under consideration) are implemented in the future (see Table 3). ${ }^{14}$ For many of the leading states (with the exception of California, which is described separately in Table 3), the Low Case scenario assumes a continuation of current spending and savings levels e.g., states achieve the spending/savings levels from the most-recently approved energy efficiency program plan or integrated resource plan, but do not exceed those levels in subsequent years. For the High Case, annual electric savings in leading states generally rises to at least $1.5 \%-2.5 \%$ of retail sales by 2020 , depending on the region, with spending increasing to $3 \%-6 \%$ of revenues from retail electricity sales.

Most of the up-and-coming states have recently enacted EEPS policies. For those states (Colorado, Michigan, New Mexico, Pennsylvania) with EEPS savings targets that rise to a level consistent with what is currently being achieved in many leading states (i.e., roughly $1.0 \%$ of retail sales per year), we assume that the EEPS savings targets are achieved in both the Low and Medium cases, and that somewhat higher savings levels (1.2\% to $1.5 \%$ of retail sales) are reached in the High Case scenario. For other up-and-coming states with EEPS policies (Ohio, Illinois, Maryland, and Virginia), we make more conservative assumptions, based on a number of different considerations. ${ }^{15}$ 
For the uncommitted states, we employ a standardized (and admittedly speculative) set of assumptions regarding the extent to which these states increase their support for ratepayerfunded energy efficiency programs in the future (see Table 3). In each scenario, energy efficiency program spending is assumed to increase linearly to a target percentage of revenues by a specified year $(0.3 \%$ of revenues by 2020 in the Low Case, $0.5 \%$ by 2012 in the Medium Case, and $0.8 \%$ by 2020 in the High Case). The High Case corresponds roughly to a scenario in which uncommitted states reach current national average spending levels by 2020 (and thus is well below what could be cost-effectively achieved in these states). Somewhat greater spending levels are assumed for Florida compared to the other uncommitted states, as its current spending levels are moderately higher than the other states in this group. Also, for many leading and upand-coming states, energy efficiency spending by publicly owned utilities (i.e., municipal utilities and rural electric cooperatives) was projected using the same scenario definitions as for the uncommitted states. This convention reflects the fact that publicly owned utilities are generally not subject to the same energy efficiency saving and spending policies as investorowned utilities, and thus (in some states, at least) have historically provided less aggressive support for energy efficiency than their investor owned counterparts.

Table 2. Key Policy Drivers for Energy Efficiency Spending and Savings Projections

\begin{tabular}{|ll|}
\hline Policy Drivers & Applicable States* \\
\hline $\begin{array}{l}\text { Statutory requirement that utilities acquire all cost- } \\
\text { effective energy efficiency }\end{array}$ & CA, CT, MA, RI, WA \\
\hline EEPS & $\begin{array}{l}\text { CA, CO, IL, MD, MN, MI, NJ (proposed), NM, NY, } \\
\text { OH, PA, TX, VA (provisional), WI (proposed) }\end{array}$ \\
\hline Energy efficiency eligibility under state RPS & HI, NC, NV \\
\hline Recently-approved IRP plan & CO, ID, OR, MT, UT \\
\hline Recently-approved DSM plan or multi-year budget & AZ, CT, CO, IA, MA, ME, NJ, RI (proposed), VT \\
\hline System benefit charge & DC \\
\hline
\end{tabular}

* The Applicable States listed for each policy represents the states for which that policy informed development of spending and savings projections; it does not necessarily represent the totality of all states with that particular policy.

\section{Table 3. Scenario Assumptions Underlying Electric EE Spending and Savings Projections}

\begin{tabular}{|c|c|c|}
\hline $\begin{array}{l}\text { Group of } \\
\text { States }\end{array}$ & Scenario & Representative Assumptions (specific assumptions vary by state) \\
\hline \multirow{3}{*}{$\begin{array}{l}\text { Leaders } \\
\text { (non-CA) }\end{array}$} & Low & $\begin{array}{l}\text { States generally meet existing EEPS targets or savings levels identified in approved IRPs or } \\
\text { maintain spending at existing levels, based on current SBC or approved DSM plan }\end{array}$ \\
\hline & Medium & $\begin{array}{l}\text { Highly state-specific: an approximate doubling of current spending for many New England } \\
\text { states by 2020; no change from low case for some Northwestern states; NY meets its EEPS }\end{array}$ \\
\hline & High & $\begin{array}{l}\text { States generally reach benchmark } 2020 \text { savings level for region }(2.0-2.5 \% \text { of retail sales for } \\
\text { most New England states, } 1.5 \% \text { for Northwest states); NY spending reaches } 3.5 \% \text { of revenues } \\
\text { by 2020; NJ and WI adopt and meet proposed EEPS targets }\end{array}$ \\
\hline \multirow{3}{*}{ California } & Low & $\begin{array}{l}\text { IOU annual savings equal to current long-term savings goals through 2020; POUs' annual } \\
\text { savings equal } 75 \% \text { of the average annual savings identified in their } 10-y r \text {. EE plans }\end{array}$ \\
\hline & Medium & $\begin{array}{l}\text { IOU savings same as low case; POUs attain } 100 \% \text { of the annual savings levels identified in } \\
\text { their } 10 \text {-yr plans }\end{array}$ \\
\hline & High & $\begin{array}{l}\text { IOUs maintain savings at } 2008 \text { goal level through 2020; POU savings are same as in medium } \\
\text { case }\end{array}$ \\
\hline \multirow{3}{*}{$\begin{array}{l}\text { Up-and- } \\
\text { Comers }\end{array}$} & Low & $\begin{array}{l}\text { Similar to low case assumptions for Leading states, but EEPS targets are not achieved in IL or } \\
\text { OH }\end{array}$ \\
\hline & Medium & $\begin{array}{l}\text { No change from low case for many states; } 2020 \text { savings increase to approx. } 0.7 \%-1.0 \% \text { of } \\
\text { retail sales in several others }\end{array}$ \\
\hline & High & $\begin{array}{l}\text { Savings in most states reach } 1.0-1.5 \% \text { of retail sales by } 2020 \text {; IL fully meets its EEPS targets; } \\
\text { TX reaches annual savings of } 1.0 \% \text { of retail sales by } 2020\end{array}$ \\
\hline Uncommitted & Low & Spending increases linearly from $0.1 \%$ of revenues in 2008 to $0.3 \%$ in 2020 ; FL spending \\
\hline
\end{tabular}




\begin{tabular}{|l|l|l|}
\hline \multirow{3}{*}{ States } & & remains flat at $0.4 \%$ of revenues from 2008-2020 \\
\cline { 2 - 3 } & Medium & $\begin{array}{l}\text { Spending increases linearly from 0.1\% of revenues (0.4\% in FL) in 2008 to 0.5\% in 2012, and } \\
\text { remains flat thereafter }\end{array}$ \\
\cline { 2 - 3 } & High & Spending increases linearly from 0.1\% of revenues (0.4\% in FL) in 2008 to 0.8\% in 2020 \\
\hline
\end{tabular}

B. Results

Across the set of scenarios developed, ratepayer-funding for energy efficiency is projected to increase from \$3.1 billion in 2008 to $\$ 4.1-\$ 8.8$ billion in 2015 and to $\$ 5.4-\$ 12.4$ billion in 2020, depending on the scenario (see Table 4 and Figure 1). Under the medium case scenario, spending reaches $\$ 6.0$ billion in 2015 and $\$ 7.5$ billion in 2020. As a percentage of total revenue from electricity and natural gas retail sales to end-use customers, spending in 2020 is projected to reach $0.8 \%$ of total revenues in the Low Case, $1.1 \%$ in the Medium Case, and $1.8 \%$ in the High Case - compared to $0.6 \%$ in 2008 . Under all three scenarios, funding for electric energy efficiency is expected to represent approximately $90 \%$ of the total for electric and natural gas energy efficiency, which is roughly consistent with the historical funding distribution and is indicative of the much greater emphasis of recent state energy efficiency policies on the electric sector.

Table 4. Range in Ratepayer-Funding Projections for 2015 and 2020

\begin{tabular}{|c|ccc|ccc|}
\hline & \multicolumn{3}{|c|}{ Spending (\$billion, nominal) } & \multicolumn{3}{c|}{ Spending (\% of revenues) } \\
& $2008^{\star}$ & 2015 & 2020 & $2008^{\star}$ & 2015 & 2020 \\
\hline Electric & 2.6 & $3.7-7.8$ & $4.9-10.9$ & $0.7 \%$ & $1.0 \%-2.0 \%$ & $1.0 \%-2.2 \%$ \\
Gas & 0.5 & $0.4-1.0$ & $0.5-1.6$ & $0.3 \%$ & $0.3 \%-0.7 \%$ & $0.2 \%-0.8 \%$ \\
Total & 3.1 & $4.1-8.8$ & $5.4-12.4$ & $0.6 \%$ & $0.8 \%-1.6 \%$ & $0.8 \%-1.8 \%$ \\
\hline
\end{tabular}

* 2008 data represent approved program budgets rather than actual spending, which is not yet known; source for 2008 dollar values: Consortium for Energy Efficiency (CEE)

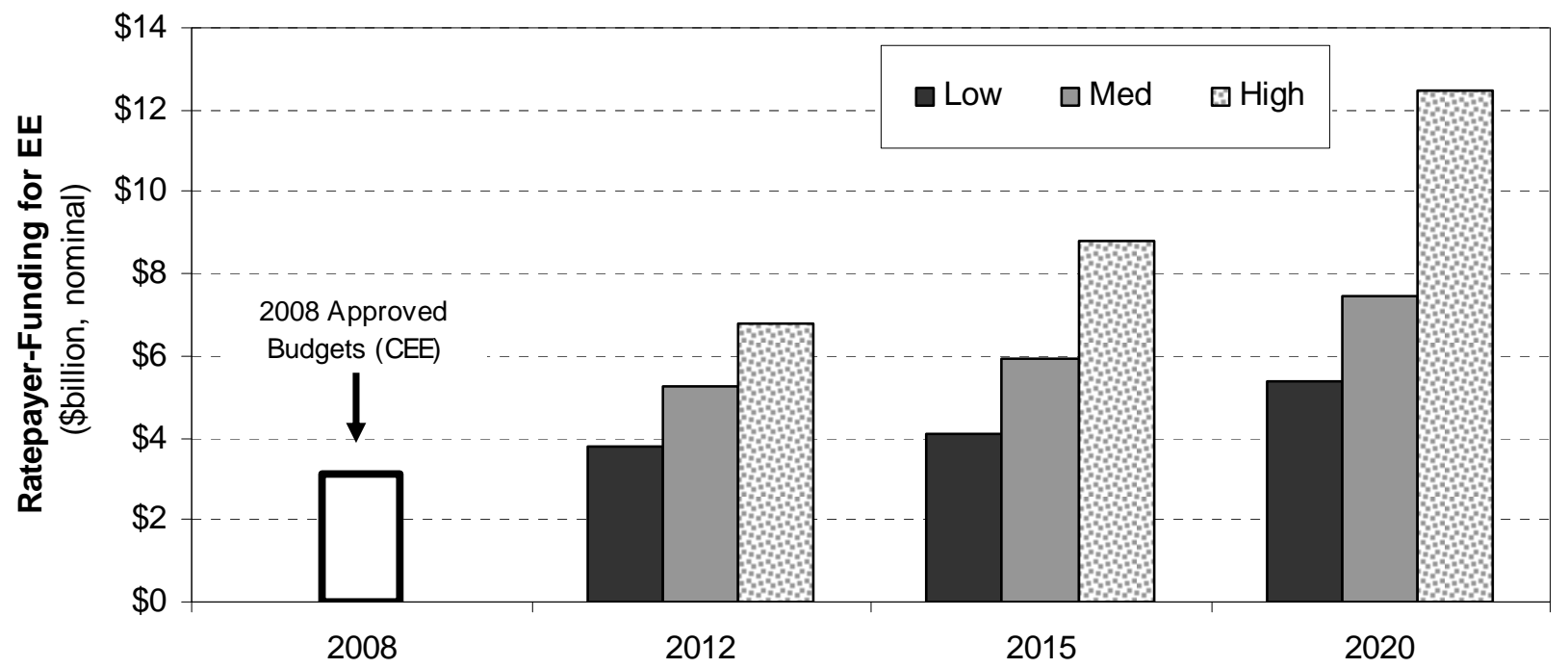

Figure 1. Projected Ratepayer-Funding for Electric and Natural Gas Energy Efficiency Programs in the U.S. 
Broad adoption of new state-level energy efficiency policies also raises the prospect for significant geographical re-alignment of energy efficiency markets. Table 5 lists the 10 states with the highest projected levels of ratepayer-funding in 2020 under the Low and High Case scenarios, compared to the top 10 states in 2008, along with aggregate spending in the other 40 states. Several specific trends are worth highlighting. First, as new state energy efficiency portfolio standards are implemented, a number of states with large populations that, heretofore, have been relatively minor players on the national energy efficiency stage (e.g. PA, IL, OH, MI) assume much more prominent roles by 2020. Second, across all three scenarios, California remains the largest market, but funding levels become markedly more evenly distributed among leading states, with all of the top-10 states reaching projected funding levels in excess of \$200M per year in the Low Case and $\$ 400 \mathrm{M} / \mathrm{yr}$ in the High Case. Energy efficiency spending also becomes considerably more evenly distributed at a national level, with a much greater percentage of future energy efficiency spending projected to occur outside of the top 10 states than is currently the case (i.e., $41-42 \%$ by 2020 compared to $22 \%$ today).

Table 5. Top-10 Energy Efficiency Markets in 2020, Ranked by Annual Budget Projections

\begin{tabular}{|c|c|c|c|c|c|c|}
\hline \multirow{3}{*}{ Rank } & \multirow{2}{*}{\multicolumn{2}{|c|}{$\begin{array}{l}2008 \text { Budget } \\
\text { (\$M, nominal) }\end{array}$}} & \multicolumn{4}{|c|}{2020 Spending Projections } \\
\hline & & & \multicolumn{2}{|c|}{ Low (\$M, nominal) } & \multicolumn{2}{|c|}{ High (\$M, nominal) } \\
\hline & $\mathrm{CA}$ & 1,014 & $\mathrm{CA}$ & 492 & $\mathrm{CA}$ & 1,312 \\
\hline 2 & NY & 288 & NY & 477 & NY & 1,094 \\
\hline 3 & NJ & 196 & $\mathrm{OH}$ & 350 & TX & 882 \\
\hline 4 & WA & 179 & $\mathrm{NJ}$ & 344 & IL & 805 \\
\hline 5 & MA & 149 & MA & 297 & MA & 630 \\
\hline 6 & WI & 140 & $\mathrm{NC}$ & 273 & $\mathrm{OH}$ & 595 \\
\hline 7 & MN & 137 & PA & 247 & WI & 575 \\
\hline 8 & $\mathrm{FL}$ & 124 & MI & 238 & $\mathrm{NJ}$ & 504 \\
\hline 9 & $\mathrm{CT}$ & 114 & IL & 230 & PA & 467 \\
\hline 10 & $\mathrm{TX}$ & 106 & WA & 202 & $\mathrm{MN}$ & 413 \\
\hline Top-10 (\$M) & \multicolumn{2}{|c|}{2,447} & \multicolumn{2}{|c|}{3,150} & \multicolumn{2}{|c|}{7,276} \\
\hline$\%$ of U.S. & \multicolumn{2}{|c|}{$78 \%$} & \multicolumn{2}{|c|}{$59 \%$} & \multicolumn{2}{|c|}{$58 \%$} \\
\hline Other States (\$M) & \multicolumn{2}{|c|}{686} & \multicolumn{2}{|c|}{2,211} & \multicolumn{2}{|c|}{5,168} \\
\hline$\%$ of U.S. & \multicolumn{2}{|c|}{$22 \%$} & \multicolumn{2}{|c|}{$41 \%$} & \multicolumn{2}{|c|}{$42 \%$} \\
\hline
\end{tabular}

Recently adopted energy efficiency policies in many states will require quite dramatic increases in spending over the next decade, which, for up-and-coming states, will be built from a modest base. Table 6 lists the 10 states with the largest projected funding increases from 2008 to 2020. In the Low Case, spending increases by $\$ 100 \mathrm{M}-\$ 300 \mathrm{M}$ in 10 states over the decade. Only three of these states (NY, MA, and NJ) had significant energy efficiency budgets in 2008; the others are all up-and-coming states with recently enacted EEPS policies (or, in North Carolina, an RPS policy in which energy efficiency is a qualifying resource). In the High Case, more than 10 states register spending increases in excess of $\$ 300 \mathrm{M}$ by 2020, with three large states (NY, TX, and $\mathrm{IL}$ ) seeing an increase of greater than $\$ 750 \mathrm{M}$. In a later section of this paper, we discuss some of the issues that states may confront as they seek to dramatically ramp-up energy efficiency program activity.

Table 6. States with Largest Projected Funding Increase (2008-2020)

\begin{tabular}{|l|lr|r|}
\hline \multirow{2}{*}{ Rank } & \multicolumn{2}{|c|}{ Low Case (\$M, nominal) } & \multicolumn{2}{c|}{ High Case (\$M, nominal) } \\
\cline { 2 - 4 } & \multicolumn{2}{|c|}{2008 2008-2020 } & 2008 2008-2020 \\
\hline
\end{tabular}




\begin{tabular}{|c|c|c|c|c|c|c|}
\hline & & Budget & Increase & & Budget & Increase \\
\hline 1 & $\mathrm{OH}$ & 58 & 292 & NY & 288 & 806 \\
\hline 2 & $\mathrm{NC}$ & 0 & 273 & $\mathrm{TX}$ & 106 & 775 \\
\hline 3 & PA & 0 & 247 & $\mathrm{IL}$ & 41 & 764 \\
\hline 4 & $\mathrm{MI}$ & 20 & 218 & $\mathrm{OH}$ & 58 & 537 \\
\hline 5 & NY & 288 & 189 & MA & 149 & 481 \\
\hline 6 & IL & 41 & 189 & PA & 0 & 467 \\
\hline 7 & MA & 149 & 148 & WI & 140 & 435 \\
\hline 8 & $\mathrm{NJ}$ & 196 & 148 & MD & 6 & 348 \\
\hline 9 & MD & 6 & 143 & $\mathrm{NC}$ & 0 & 324 \\
\hline 10 & $\mathrm{CO}$ & 26 & 141 & $\mathrm{MI}$ & 20 & 313 \\
\hline Top-10 Total & & 784 & 1,988 & & 808 & 5,250 \\
\hline Other States & & 2,348 & 241 & & 2,324 & 4,062 \\
\hline
\end{tabular}

\section{Projected Electricity Savings in Perspective}

In 2008, electric energy efficiency programs are estimated to have resulted in incremental annual savings of approximately 13 billion $\mathrm{kWh}$, equivalent to $0.34 \%$ of total retail electricity sales nationally in that year. ${ }^{16}$ Several leading states have achieved incremental annual savings greater than $1.0 \%$ of retail energy sales, and VT reported annual energy savings in 2008 equivalent to $2.5 \%$ of retail energy sales. ${ }^{17}$

Projected increases in ratepayer spending on energy efficiency programs over the next decade are expected to result in significant increases in energy savings. Figure 2 shows our projections of incremental annual savings as a percentage of retail electricity sales, for the three scenarios. From 2010-2020, average annual savings range from $0.41 \%$ of retail sales in the Low Case to 0.76\% in the High Case. In comparison, EIA's April 2009 reference case forecast (which does not explicitly account for ratepayer-funded energy efficiency) projects that retail electricity sales will grow at an average rate of $1.1 \%$ per year over this period. Cumulatively, electricity savings achieved from ratepayer-funded programs implemented over the 2010-2020 period are projected to reduce U.S. electricity consumption in 2020 by about $4.7 \%$ (relative to EIA's reference case forecast of 2020 retail electricity sales) in the Low Case, and by about $8.6 \%$ in the High Case. Approximately $90 \%$ of all savings is projected to occur within leading and up-and-coming states that have already made a significant commitment to supporting ratepayer-funded energy efficiency. 


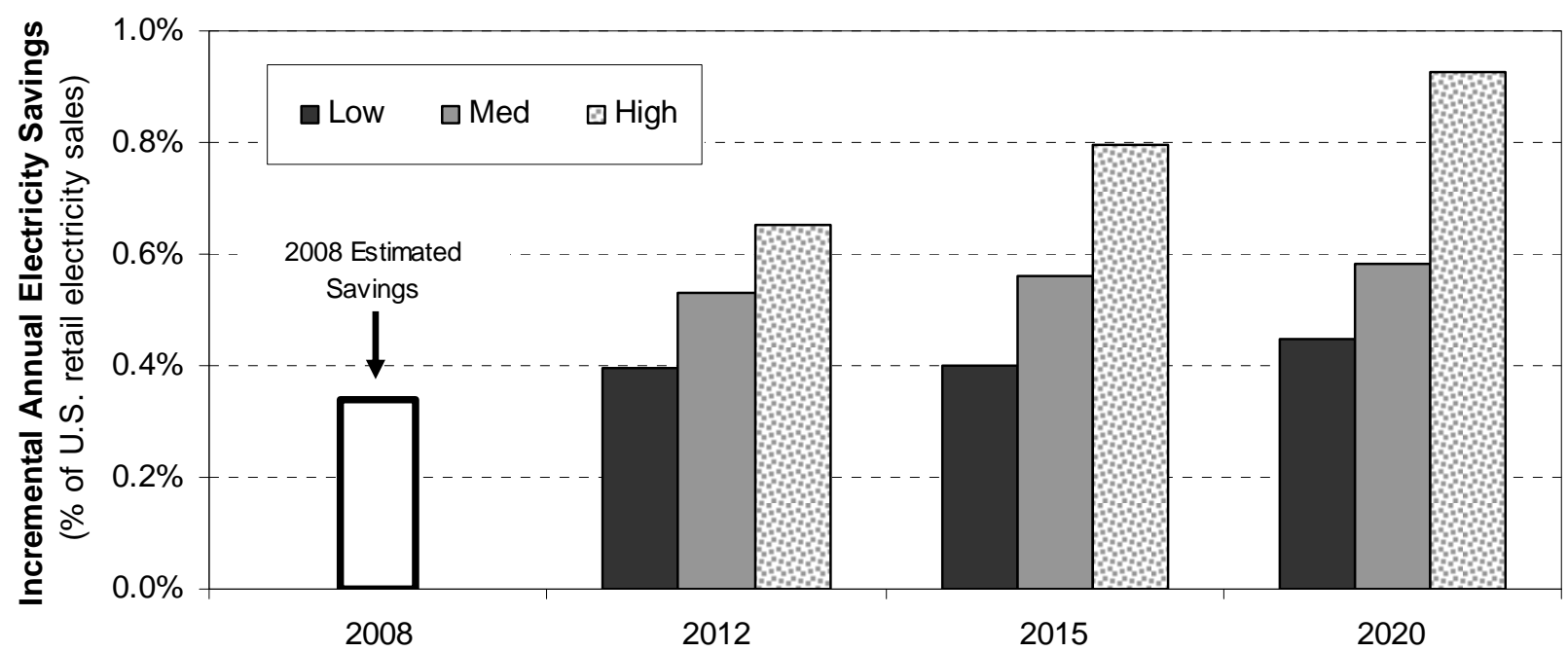

Figure 2. Projected Incremental Annual Electric Energy Efficiency Savings from Ratepayer-Funded Programs in the U.S.

A. Incremental Impact of a National EEPS or Clean Energy Standard

Several national EEPS proposals have been introduced in the U.S. Congress in 2009, and several proposed national clean energy standards - including the American Clean Energy and Security Act of 2009, which recently passed the House of Representatives - would allow energy efficiency to be used to meet a portion of the overall target in each year. Our projections of state-level energy efficiency program savings do not explicitly account for the effects of future national energy efficiency legislation and can therefore serve as a benchmark for assessing the potential incremental impact of such policies.

We estimate the incremental increase in savings from ratepayer-funded electric energy efficiency programs that could occur under several "generic" national EEPS (or clean energy standards) policies, which are modeled on recent federal legislative proposals. Under the generic policies, all retail electricity distributers with greater than 1 million MWh sales per year, on average, would be required to meet specified cumulative electric savings targets by 2020 . We consider three potential cumulative savings targets, equal to 5\%, $10 \%$, and $15 \%$ of retail electricity sales in 2020. Only savings from measures implemented in 2010 or later would count towards the targets. Compliance could be achieved through utility energy efficiency programs, new building energy codes, new appliance efficiency standards, new combined heat and power, and distribution system upgrades. The policy would not create a national market for tradable energy efficiency certificates; however, it would allow obligated retail electricity distributers to meet a portion of their EEPS obligations by purchasing electricity savings from measures implemented in the same state, via bilateral contracts with other distribution utilities, state agencies, or other energy efficiency program providers.

To determine the incremental increase in savings from ratepayer-funded electric energy efficiency programs that would be required under these generic EEPS proposals, we assume that half of the total energy savings target in each state would be met through ratepayer-funded 
programs, and the remaining half would be met through a combination of codes and standards, CHP, distribution system upgrades, and other eligible measures. We further assume that bilateral contracting for electricity savings from measures implemented within each state occurs freely without constraint. Given these assumptions, we estimate that a 5\% national EEPS would require a $0-12 \%$ increase in savings from ratepayer-funded energy efficiency programs (where the lower percentage number represents the increase relative to our High Case savings projection, and the higher percentage number represents the increase relative to our Low Case savings projection). Similarly, we estimate that a 10\% national EEPS would require an 8-37\% increase, and a 15\% national EEPS would require an 18-68\% increase (see Table 7). If states were to rely more heavily on utility programs than we assume, or if intra-state bilateral contracting of energy efficiency savings for compliance with the national EEPS were constrained, then larger percentage increases would be needed. Moreover, the percentage savings increases presented here represent the aggregate national increase. Naturally, the additional savings required in individual states may be substantially higher or lower than the national average, depending on what portion of the state's retail electricity sales is exempt from the EEPS, and on the amount of savings that would occur in the absence of a national EEPS.

\section{Table 7. Projected Incremental Impact of a National EEPS on Ratepayer-Funded Energy Efficiency Program Savings}

\begin{tabular}{|c|c|}
\hline $\begin{array}{c}\text { National EEPS Saving Target: } \\
\text { Cumulative Savings in 2020 as a } \\
\text { Percent of Retail Sales }\end{array}$ & $\begin{array}{c}\text { Percentage Increase in EE } \\
\text { Program Savings Relative to } \\
\text { No National EEPS }\end{array}$ \\
\hline $5 \%$ & $0 \%-12 \%$ \\
\hline $10 \%$ & $8 \%-37 \%$ \\
\hline $15 \%$ & $18 \%-68 \%$ \\
\hline
\end{tabular}

Although our analysis is based on a single generic national EEPS policy, it does reveal that a relatively aggressive national EEPS (e.g., a cumulative savings target on the order of $15 \%$ of retail sales by 2020) could require substantial increases in energy savings, even in the face of the spate of aggressive state policies that have recently been adopted. The impact, however, would likely fall primarily on about 20 or so states that have not yet made significant commitments to supporting ratepayer-funded energy efficiency. In addition, the incremental impact of a national EEPS depends heavily on its design - e.g., overall target levels, the set of eligible measures, and allowances for bilateral contracting and/or trading of energy savings certificates. In particular, allowing unrestricted trade of energy savings certificates, without a sufficiently aggressive target, could substantially degrade the incremental impact of a national EEPS. ${ }^{18}$

\section{B. Contribution to Greenhouse Gas Emission Reduction Targets}

Understanding the potential range of energy savings resulting from ratepayer-funded efficiency programs over the next decade is also important from the perspective of gauging their contribution to future carbon emission reduction targets that Congress may adopt. For example, The American Clean Energy and Security Act of 2009, which recently passed the U.S. House of Representatives, would place a cap on greenhouse gas emissions for certain sectors of the U.S. economy. ${ }^{19}$ Based on a preliminary analysis by the Environmental Protection Agency (EPA), meeting the 2020 cap under this bill would require a reduction of roughly 950 million metric tons of carbon dioxide equivalent $\left(\mathrm{mmtCO}_{2} \mathrm{e}\right)$, relative to projected 2020 emissions under the 
reference case scenario. $^{20}$ It is unknown to what extent EPA's reference case forecast implicitly accounts for electricity savings from future ratepayer-funded energy efficiency programs. Lacking specific knowledge, if we assume that the reference case includes a continuation of ratepayer-funded energy efficiency savings at $50 \%$ of the level achieved in 2008, then our projections of electricity savings from ratepayer-funded programs would yield emission reductions in the range of $42-164 \mathrm{mmtCO}_{2} \mathrm{e}$ by 2020 , relative to the reference case. ${ }^{21}$ Though not a negligible impact, it is clear that even the fairly aggressive increases in energy efficiency spending and savings that we project over the next decade would contribute a relatively moderate percentage to the overall emission reductions that future federal climate regulations might potentially require. That said, ratepayer-funded energy efficiency programs represent just one strategy for acquiring energy efficiency savings; accounting for the effects of new building codes, appliance efficiency standards, tax incentives and other federal programs would increase the total contribution of energy efficiency towards any future greenhouse gas emission reduction goals.

\section{Challenges Ahead, Bumps in the Road?}

Is a doubling or tripling of ratepayer-funding for energy efficiency over the next decade feasible? What are the fundamental challenges that confront states' efforts to achieve increasing levels of savings from ratepayer-funded programs? Below, we highlight several issues that we believe may dominate the landscape on the road ahead.

\section{A. The Economic Downturn}

At least over the near-term, economic conditions in the U.S. may complicate and constrain efforts to scale-up energy efficiency spending and savings, for several reasons. First, the success of ratepayer-funded energy efficiency programs typically requires customers to pay a portion of the capital outlay for energy efficiency measures. As households and businesses struggle to manage their day-to-day expenses, many may be reluctant make new investments, even those with short payback periods. Second, a slowing or decline in overall economic activity will likely reduce the rate of stock turnover and new housing starts, thereby reducing the amount of energy savings that could be captured through ratepayer-funded programs targeting these market opportunities. Finally, economic hard-times may complicate the political feasibility of increasing ratepayer-spending for energy efficiency, particularly if it results in short-term rate impacts. $^{22}$

\section{B. Aversion to Short-Term Rate Impacts from Large-Scale Energy Efficiency Implementation}

In most states, utilities typically expense program costs for energy efficiency as they are incurred, hence cost recovery is relatively front-loaded compared to cost recovery for most supply-side resource alternatives. As a result, the rate impacts from energy efficiency tend to occur sooner (even if the rate impacts are less over the long-term, and even if average utility bills are reduced compared to supply-side alternatives). Thus, the short-term rate impacts associated with attaining very aggressive levels of savings could pose a political challenge for state regulators, particularly in those states that have seen significant rate hikes in recent years or 
whose rates are well-above national averages. This issue has surfaced in several states that have recently passed an EERS (e.g. IL, PA) as they have established cost caps or limits on rate impacts. To mitigate concerns about short-term rate impacts, we expect that an increasing number of state PUCs and utilities will explore cost recovery mechanisms that allow better alignment of program costs and system benefits (e.g. amortization of expenses) as well as decoupling and shareholder incentive mechanisms.

\section{Coordination with State/Federal Energy Efficiency Programs}

In most states and market segments, ratepayer-funded energy efficiency programs administered by utilities or third parties have been implemented at a much larger scale than state or Federal energy efficiency programs (except for low-income weatherization). The passage of The American Recovery and Reinvestment Act (ARRA) is clearly a "game-changer" in terms of the level of support and funding provided by Federal taxpayers for energy efficiency over the next three years. Funding for the federal low-income weatherization program (\$5 billion) and State Energy Program (SEP) formula grants (\$3.1 billion targeting energy efficiency retrofits and renewable energy in buildings and industrial facilities) will increase ten-fold from current levels, and the Energy Efficiency and Conservation Block Grant Program will provide an additional $\$ 3.2$ billion in grants to local governments for various energy efficiency and renewable energy activities. The intent of the SEP formula grants, specifically, is for states to commit their grant funding to expand existing programs, including ratepayer-funded programs, or to create new programs - not to supplant or replace existing funding. ${ }^{23}$ Thus, state and local energy efficiency programs that are implemented with ARRA funds will require a massive ramp-up in capability to deliver energy efficiency services.

Because we are primarily interested in forecasting longer-term trends in ratepayer-funded energy efficiency programs, our analysis does not explicitly account for the potential short-term impacts of ARRA-funded state and local EE programs on existing and emerging ratepayer-funded EE programs. However, the infusion of funding for energy efficiency provided by ARRA does present several near-term implications for ratepayer-funded programs. First and foremost, a much higher degree of coordination will be required among energy efficiency program administrators in each state (e.g. utilities, state energy office, local governments) in order to ensure consistency in program offerings, obtain support from trade allies, and minimize confusion among customers and program delivery contractors. Because customers will have access to multiple funding sources to buy-down the cost of their energy efficiency projects (e.g. ratepayer and ARRA funds), state PUCs will have to develop guidelines regarding whether program administrators will be able to take full or partial credit for savings funded by different programs. ${ }^{24}$ In addition, if state PUCs perceive that end users and the service delivery infrastructure will not be able to absorb the massive increase in funds for energy efficiency because of the ARRA, then some states may delay or slow down their internal plans to ramp-up spending on ratepayer-funded energy efficiency programs until after ARRA funds are committed or spent (2012).

D. Developing Innovative Program Designs to Reach Deeper and Broader Savings 
Given the historic experience of leading states, we are confident that the 20 or so uncommitted states can achieve the energy efficiency savings levels in our High Case scenario (i.e., annual savings of approximately $0.3 \%$ of electric retail sales by 2020), because many utilities across a diverse set of circumstances are currently implementing programs that produce significantly greater levels of savings on a sustained basis. However, a number of leading and up-and-coming states have established aggressive energy efficiency savings goals for future years that are well beyond current experience and practice in most leading states (e.g., annual electric savings on the order of $2 \%$ or more of retail sales). Based on recent market potential studies in several of these states, savings at this level are achievable and cost-effective compared to supply-side alternatives. However, the challenge for program administrators will be to design and implement programs that can achieve both deeper savings, on average, at customer facilities and have a broader reach in terms of market penetration, over a sustained period of time. Service providers will have to achieve savings levels of $25-40 \%$ of existing usage at customer facilities compared to current practice in ratepayer-funded programs, which is typically in the 5-20\% range. Achieving higher market penetration rates will require programs to target and reach traditionally under-served markets in far greater numbers than current practice (e.g. small commercial, multifamily, rental housing, non-owner occupied commercial facilities). ${ }^{25}$ We are also likely to see increased attention to integrated delivery of electric and gas efficiency programs as well as coordinated delivery of energy efficiency and on-site renewables and combined heat and power, in order to reduce transaction costs and provide customers with tailored, customized service offerings.

\section{E. Greater Reliance on Aggressive Appliance and Lighting Efficiency Standards}

Ratepayer-funded (or taxpayer-funded) energy efficiency programs, federal and state appliance efficiency standards, and building codes represent three major strategies to capture energy efficiency savings potential. These three strategies can complement each other but also are partial substitutes, in the sense that adoption of aggressive minimum efficiency standards for a broad range of consumer products raises the current-practice baseline and may therefore reduce the remaining achievable potential that can be captured by voluntary, ratepayer-funded energy efficiency programs.

For example, in the 2007 energy bill, new standards were adopted for 10 products, including general service lamps, which are required to use about 25-30\% less energy than current incandescent bulbs by $2012-14$ and $60 \%$ less by $2020 .^{26}$ When fully phased in, the new standard for general service lamps, combined with increasing market penetration of compact fluorescents lighting (CFLs), may mean that CFLs applications that are eligible measures in many ratepayerfunded programs will have become standard practice. Residential lighting measures often account for $20-40 \%$ of total savings in a utility's energy efficiency portfolio and are among the most cost-effective measures. Thus, in the future, program administrators will likely be required to support new measures (e.g., LED lighting) and develop new strategies to capture costeffective savings opportunities, because some of the measures implemented currently in programs (e.g. standard CFLs) may be covered by appliance efficiency standards.

Our analysis of future spending and savings scenarios for ratepayer-funded EE programs does not explicitly account for the possibility that federal and/or state governments could decide to 
significantly revise the balance among existing EE policies and decide to rely more heavily on building energy codes and efficiency standards to capture the available savings potential. We recognize that this is a important issue, though, and note that the California PUC, in adopting new savings goals for ratepayer-funded energy efficiency programs for the 2009-2020 period, explicitly accounted for the impacts of new federal standards and state codes and standards. The CPUC correspondingly reduced the remaining market potential for ratepayer-funded energy efficiency programs. It is possible that energy efficiency goals in other states have not fully accounted for the impact of federal appliance standards, if these goals were based on market potential studies conducted prior to enactment of those standards. At the same time, new efficiency opportunities may emerge over the coming decade that will replenish the market potential reservoir.

F. Developing the Institutional Framework for Energy Efficiency in Up-and-Coming and Uncommitted States

Energy efficiency resources have some distinctive characteristics that require state PUCs to establish an institutional framework for effective regulatory oversight of ratepayer-funded energy efficiency programs. These distinctive elements include: the need for measurement and verification of savings from energy efficiency programs; the fact that energy efficiency programs depend on customer acceptance and adoption; and the fact that, under traditional regulation, the utility's financial interests are not well-aligned with societal interest in pursuing cost-effective efficiency. Many leading states have successfully grappled with these institutional and regulatory policy issues, and a variety of approaches have proven to be effective. Based on this experience, state PUCs must provide leadership in defining energy efficiency policy objectives, establish roles and responsibilities for program administrators, and be willing to devote sufficient staff (or technical consultant) resources so that they can effectively oversee acquisition of largescale energy efficiency resources.

\section{G. Workforce Needs and Human Infrastructure}

The projected growth in ratepayer- and taxpayer-funded energy efficiency will require significant near- and long-term expansions of the energy efficiency services sector (EESS) workforce. Trained personnel are and will be needed to design, implement, and manage energy efficiency programs, and to design, construct, install and maintain energy efficiency building systems. There is growing concern among policymakers and program administrators about a shortage of well-trained personnel in the EESS. Goldman et al. (2009) attempted to estimate the size and structure of the current EESS workforce, forecast the number of people that will be needed in 2015 and 2020 under various scenarios, and assess shortages and needs in the current workforce in light of expectations for growth. ${ }^{27}$

Drawing upon over 300 interviews, survey respondents reported that:

- management positions requiring at least 10 years experience and positions requiring engineering experience with high-efficiency technologies are the most difficult positions to fill (taking up to 12-15 months to fill); 
- re-training of the existing construction and building industry workforce to provide energy efficiency services will be critical to success (and that this workforce is "under-employed" given the economic downturn);

- aging workforce is viewed as a problem among building and construction industry association members (40-45\% of workforce is over 50) but not in other EESS workforce segments;

- there is a shortage of engineers with efficiency knowledge or experience and energy efficiency services employers are thus willing to hire any engineer with technical aptitude, communication skills and some engineering experience;

- there are not enough certificates or degrees being awarded in energy efficiency related training and education to meet the growing need, although the training/education capability is expanding.

In our view, the combined impact of ratepayer-funded programs and energy efficiency programs that will be funded by the ARRA means that the shortage of well-trained personnel is primarily a near-term issue (e.g. 1-3 years). By 2013, if energy efficiency programs that are funded by the ARRA wind down, there will be a much larger workforce base in the EESS, which should be able to meet workforce demands that would occur under our High Case projection of ratepayerfunded energy efficiency program spending.

\section{Conclusions}

A proliferation of new state-level energy efficiency policies enacted over the past several years suggests that ratepayer-funded energy efficiency program savings and spending will continue to grow at a brisk pace over the next decade, and that the geographical structure of the energy efficiency market will undergo a fairly dramatic re-alignment. Based on a bottom-up analysis of state-level energy efficiency policies, we project that ratepayer-funding for electric and gas energy efficiency programs will rise from $\$ 3.1$ billion in 2008 to between $\$ 5.4$ billion (Low Case) and $\$ 12.4$ billion (High Case) by 2020, with a Medium Case estimate of $\$ 7.5$ billion. Along with the increase in aggregate spending, we project a significant broadening of the national energy efficiency market. A large portion of the overall projected increase will be centered in relatively populous states that, until recently, have been relatively minor players on the national energy efficiency stage (e.g., IL, MI, NC, OH, and PA). Thus, for example, we project in our Medium Case that 15 states will have annual energy efficiency budgets greater than $\$ 200$ million in 2020, compared to just 2 states in 2008.

Our aggregate U.S. spending projections equate to average annual growth rates of 4.6\% (Low Case), $7.5 \%$ (Medium Case), and 12.2\% (High Case). In comparison, spending grew by $18 \%$ per year, on average, from 2006-2008. Moreover, the projections do not account for recent federal stimulus funding (ARRA), the potential impact of future national energy efficiency legislation (e.g., a national EEPS or a national RPS with an energy efficiency component) or future federal climate change legislation. Thus, our Medium Case is arguably a somewhat conservative estimate of the "most likely" spending trajectory, and our High Case projection is a more probable outcome than the Low Case. 
That said, states are likely to face a number of key challenges as they seek to ramp up energy efficiency program activity. Some of these challenges are primarily near-term issues - e.g., the economic downturn, shortages within the energy efficiency workforce, and the (sometimes painstaking) process of developing the requisite institutional infrastructure and regulatory oversight mechanisms in states that are in the early phases of implementing ratepayer-funded efficiency programs. Other issues are ongoing or longer-term, such as the need to develop new and innovative program designs to achieve deeper and broader energy savings, in order to reach state energy savings goals that significantly exceed what is currently being achieved. This challenge will become increasingly pertinent as new appliance efficiency standards and building codes deplete some of the traditional low-hanging fruit for voluntary energy efficiency programs. While significant, we believe that these challenges are surmountable. 


\section{Endnotes:}

${ }^{1}$ Ratepayer-funded energy efficiency programs are variously administered by utilities, state agencies, or non-profit organizations.

2 See Nicole Hopper, Galen Barbose, Charles Goldman, and Jeff Schlegel, Energy Efficiency as a Preferred Resource: Evidence from Utility Resource Plans in the Western United States and Canada, Energy Efficiency 14(2):126-34, October 2008.

${ }^{3}$ Source: Consortium for Energy Efficiency (CEE), 2008 Energy Efficiency Industry Report, at http://www.cee1.org/ee-pe/2008. CEE compiles data on approved energy efficiency program budgets; totals reported exclude budgets for load management programs.

${ }^{4}$ See New York Public Service Commission, Order Establishing Energy Efficiency Portfolio Standard And Approving Programs, Case 07-M-0548, June 23, 2008.

${ }^{5}$ See New Jersey Board of Public Utilities, Order Establishing 2009 -2012 Funding Level, Docket Number EQO7030203, September 30, 2008.

${ }^{6}$ See Consultant report to Massachusetts Energy Efficiency Advisory Council 2009, The Context for Energy Efficiency Savings: Electric Savings Update, Electric Net Benefits and Gas Savings, March 24, 2009, at http://www.ma-eeac.org.

${ }^{7}$ See California Public Utilities Commission, California's Long-Term Energy Efficiency Strategic Plan, September 2008, at http://www.californiaenergyefficiency.com/index.shtml.

${ }^{8}$ The lower savings potential is partially a result of the high saturation of many energy efficiency measures and California's aggressive state building codes and appliance efficiency standards; which also reduces the remaining energy efficiency potential that can be obtained through utility programs.

${ }^{9}$ Utilities in several of these states (MD, IL, MI) offered energy efficiency programs in the late 1980s and early 1990s, often driven by integrated resource plans, but these energy efficiency efforts were typically abandoned with the onset of electricity restructuring.

${ }^{10}$ See Illinois Commerce Commission, Orders issued February 6, 2008 in Docket Numbers 07-0539 and 07-0540; and Maryland Public Service Commission, Orders 82383 through 82387, issued December 31, 2008 in Case Numbers 9153 through 9157.

${ }^{11}$ See Colorado Public Utilities Commission, Decision Number R08-1243, Docket Number 08A-366EG, issued December 18, 2008.

${ }^{12}$ See Nevada Power Company, 2006 Integrated Resource Plan, June 30, 2006; and Sierra Pacific Power Company, 2007 Integrated Resource Plan, June 29, 2007.

${ }^{13}$ See Arizona Public Service Company, Resource Plan Report, January 29, 2009.

${ }^{14}$ A more-complete description of the methodology used to develop the spending projections is available at http://eetd.lbl.gov/EA/EMP/ee-pubs.html.

${ }^{15}$ For example, Illinois and Ohio both have EEPS targets that rise to $2 \%$ of retail sales per year, which exceeds the level currently being achieved in virtually all leading states. Moreover, Illinois' EEPS includes a cost cap that, unless modified, is likely to preclude attainment of the statutory savings targets in later years. Ohio's EEPS contains provisions to allow many commercial and industrial customers (referred to as "mercantile customers" in the EEPS statute) to opt out of making funding contributions to the utilities' energy efficiency programs if they can demonstrate investments in energy efficiency at their facility. In Maryland, the EEPS is a voluntary goal, and may be achieved through a combination of ratepayer-funded energy efficiency programs, codes \& standards, and other types of market interventions. The Virginia EEPS has not yet been passed into law (as of June 2009), and is assumed to be achieved only in the high case.

${ }^{16}$ By "incremental annual energy savings" we refer to the annual energy savings resulting from new energy efficiency measures installed in a given year. We estimated 2008 electric energy efficiency savings by applying the savings-to-spending ratio for 2006 (based on the most recent national savings data published ACEEE) to the 2008 electric EE budget (from CEE). For ACEEE data, see Maggie Eldridge, Max Neubauer, Dan York, Shruti Vaidyanathan, Anna Chittum, and Steven Nadel, The 2008 State Energy Efficiency Scorecard, American Council for an Energy Efficient Economy, October 2008, at http://www.aceee.org/pubs/e086.htm.

${ }^{17}$ Efficiency Vermont Preliminary Annual Report, March 2009

${ }^{18}$ For a further explanation of this argument, see Joe Loper, Jeff Harris, Lowell Ungar, Steve Capanna, Selin Devranoglu, Deal or No Deal? Pros and Cons of Trading Under an Energy Efficiency Resource Standard, Alliance to Save Energy, Washington, D.C., August 2008, at http://ase.org/files/5211_file_ACEEE_SS_Paper_681_FINAL_2008.pdf. 
${ }^{19}$ The cap reduces covered greenhouse gas emissions to 20\% below 2005 levels by 2020, and 83\% below 2005 levels by 2050 .

${ }^{20}$ These results are based on the primary policy scenario (Scenario 2) of EPA's analysis of the Waxman-Markey bill; see: Environmental Protection Agency, Waxman-Markey Discussion Draft Preliminary Analysis: EPA Preliminary Analysis of the American Clean Energy and Security Act of 2009, April 2009, at http://www.epa.gov/climatechange/economics/economicanalyses.html\#wax.

${ }^{21}$ This range in emission reductions was calculated by reducing our projections of electricity savings from ratepayer-funded programs by the portion assumed to be implicit in the EPA reference forecast, yielding a range in cumulative savings over 2009-2020 equal to 116-270 billion $\mathrm{kWh}$. We then applied to that range of savings emission rates ranging from 0.36-0.86 metric tons per MWh. The emission rate range reflects uncertainty and geographical diversity in the emission rate of generation offset by future energy efficiency, with the lower end of the range equal to the emission rate of a combined cycle gas turbine (CCGT) generator and the upper end equal to the mid-point between the emission rates of CCGT and sub-critical pulverized coal generation.

${ }^{22}$ The economic recession has resulted in a significant reduction in sales of many electric utilities, in some cases resulting in negative growth rates. In this environment, some utilities are concerned about under-recovery of fixed costs (and authorized earnings) because a significant portion of their revenues are derived from volumetric-based rates. Significant increases in funding for energy efficiency may exacerbate this problem.

${ }^{23}$ See U.S. Department of Energy, Financial Assistance Funding Opportunity Notice: State Energy Program Formula Grants, March 12, 2009; section 4, pg 23.

${ }^{24} \mathrm{~A}$ few states (e.g. PA) have already decided that program administrators can take full credit for savings if customers receive a rebate from the utility, even if customers access additional funding sources.

${ }^{25}$ See Massachusetts Energy Efficiency Advisory Council, Context for Energy Efficiency Savings: Savings Levels Necessary to Achieve MA Policy Goals and Meet Legislative Requirements, March 10, 2009.

${ }^{26}$ Products for which new standards were adopted in 2007 Energy Bill include: general service lamps, reflector lamps, residential boilers, clothes washers, dishwashers, dehumidifiers, electric motors, metal halide lamp fixtures used in high-ceiling commercial and industrial applications, walk-in coolers and freezers, and external power supplies. See Appliance Standards Awareness Project factsheet at http://www.standardsasap.org/documents/2007EnergyBill_Standardsfactsheet.pdf

${ }^{27}$ See Charles Goldman, Merrian Fuller, Jane Peters, Marjorie McRae, Susan Lutzenhiser, and Matt Spahic, Energy Efficiency Services Sector: Workforce Size and Expectations for Growth, Lawrence Berkeley National Laboratory, June 2009. 